\title{
PRECISION CALENDAR-YEAR DATING OF THE ELM DECLINE IN A SPHAGNUM- PEAT BOG IN SOUTHERN SWEDEN
}

\author{
GÖRAN SKOG and JOACHIM REGNELLL
}

Department of Quaternary Geology, Lund University, S-223 63 Lund, Sweden

\begin{abstract}
The cause of the mid-Holocene elm decline in northwestern Europe and its relation to the contemporaneous transition from Mesolithic to Neolithic economy are still unclear, partly owing to the lack of a precise, calibrated chronology. Matching of a sequence of ${ }^{14} \mathrm{C}$ dates to the calibration curve in combination with accurate ${ }^{14} \mathrm{C}$ dating allows high-precision dating of paleoecological events. We have completed high-resolution dating of a Sphagnum-peat sequence from Ageröds Mosse in southernmost Sweden. The basis for selecting ${ }^{14} \mathrm{C}$ samples was pollen analysis at $1 \mathrm{~cm}$ intervals. Nine ${ }^{14} \mathrm{C}$ dates, covering an interval of $\mathrm{ca} .500$ calendar years around the elm decline, showed that this event occurred in Ageröds Mosse within a few decades ca. $3770 \mathrm{BC}$.
\end{abstract}

\section{INTRODUCTION}

Several hypotheses have been presented to explain the mid-Holocene elm decline in northwestern Europe, including climate change, soil deterioration, human influence connected with the transition from Mesolithic to Neolithic economy, and disease (e.g., Birks 1986). Precise calendar-year dating of the elm decline should provide a more accurate assessment of the synchronicity of this event, and thus aid in determining the cause(s) of the elm decline.

On the basis of a great number of ${ }^{14} \mathrm{C}$ dates from Scandinavia, Germany, Holland and the British Islands, Nilsson (1964) suggests in his classical study of Ageröds Mosse that the time of the elm decline in northwestern Europe was $5050 \mathrm{BP}$. However, to determine the degree of synchronicity of the elm decline in northwestern Europe, all chronologies of the elm decline should be calibrated. Unfortunately, there is a "wiggle" on the calibration curve (Stuiver and Becker 1993) at the time of the elm decline, producing an increased uncertainty when going from ${ }^{14} \mathrm{C}$ years to calendar years. Even with a high-precision date such as $5050 \pm 25 \mathrm{BP}$, the corresponding calendar-year interval is as large as ca. $170 \mathrm{yr}$.

The situation can be improved by dating a series of samples and matching those dates with the calibration curve (Pilcher 1991, 1993). The short-term variation in atmospheric ${ }^{14} \mathrm{C}$ concentration can be used to achieve precise calendar ages for samples whose real spacing in time is known and which cover $>50 \mathrm{yr}$ (Pearson 1986). Matching ${ }^{14} \mathrm{C}$ dates of a floating chronology to the calibration curve allows estimation of calendar-year dates with a precision of a few decades. Although a wood sample is desirable for this purpose, Clymo et al. (1990) demonstrated that it is possible to use the technique for peat and lake sediments where the deposition rate can be estimated.

Ageröds Mosse is a sphagnum peat bog with an area of $c a .1 .5 \mathrm{~km}^{2}$ in central Skåne, southernmost Sweden. There, Tage (1964) performed a thorough paleoecological study, using $33^{14} \mathrm{C}$ dates to construct the first radiocarbon chronology for the vegetation history of southernmost Sweden. The site is suitable for a closer study of the elm decline for several reasons:

1. The elm decline is distinct. Pollen percentages fall from $7 \%$ to $2 \%$ in $5 \mathrm{~cm}, 325-330 \mathrm{~cm}$ below the surface (Nilsson 1964).

2. The deposit is sphagnum peat, which is ideal for ${ }^{14} \mathrm{C}$ dating (Olsson 1986).

3. There is a high rate of peat accumulation at the time of the elm decline (ca. $50 \mathrm{~mm}$ in $100 \mathrm{yr}$ ), providing the basis for a study of high temporal resolution. 
Out of the sphagnum peat sequence in Ageröds Mosse, we chose nine samples covering ca. $500 \mathrm{cal}$ endar years. By applying the "wiggle-matching" procedure to this series, we attempt to reduce the calendar-year uncertainty for the elm decline in Ageröds Mosse from a few hundred years to a few decades.

\section{METHODS}

We collected new cores at the Nilsson site in September 1992. Four 1-m cores were taken with 0.5 $\mathrm{m}$ overlap at the interval $2.0-4.5 \mathrm{~m}$ below the bog surface, using a $100-\mathrm{mm}$ diameter Russian sampler. We took samples for pollen analysis at every $1 \mathrm{~cm}$ around the elm decline. We applied standard pollen preparation, including sieving, $\mathrm{NaOH}$ and acetolysis treatment. A minimum of 400 tree pollen grains were counted at each level. Analysis at $1-\mathrm{cm}$ intervals now showed an even more distinct elm decline (Fig. 1) than found by Nilsson (1964). The Ulmus percentages fall from 9-2\%, amounting to a $78 \%$ decrease in a time span corresponding, at most, to the thickness of the two adjacent samples. We estimated the peat accumulation rate for this interval, based on Nilsson (1964), to be ca. $0.5 \mathrm{~mm} \mathrm{yr}^{-1}$. The 2-cm interval of the two samples at the elm decline corresponds accordingly

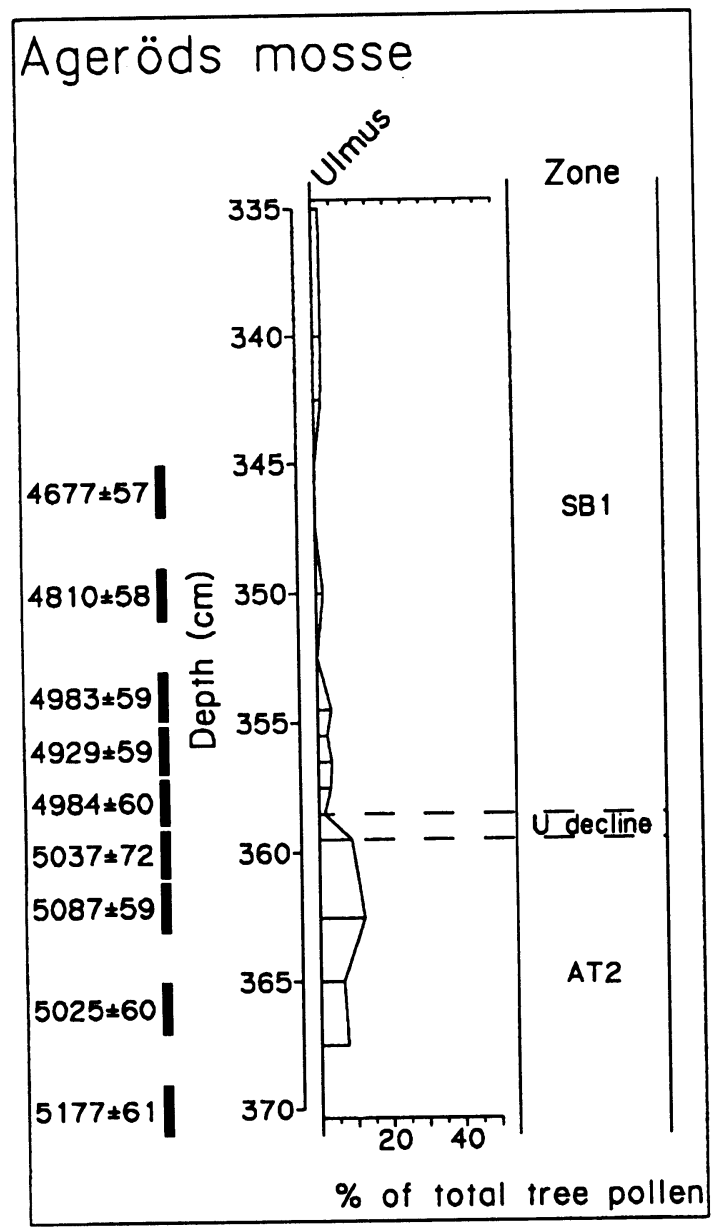

Fig. 1. Ulmus pollen curve from Ageröds Mosse at the time of the elm decline. The pollen analysis has been done at every $1 \mathrm{~cm}$. ${ }^{14} \mathrm{C}$-dated samples are indicated. 
to $c a .40 \mathrm{yr}$, which is a maximum value for the duration of the decline, as a closer pollen sampling may reveal an even smaller interval.

Guided by the pollen analysis, we picked out nine samples of peat for ${ }^{14} \mathrm{C}$ analysis. The pretreatment followed the standard acid-alkali-acid scheme. The alkali treatment consisted of $2 \mathrm{~h}$ in $2 \% \mathrm{NaOH}$ at $80^{\circ} \mathrm{C}$, which decomposed the highly humified peat samples into $70 \%$ "insoluble" and $30 \%$ soluble fractions. The ${ }^{14} \mathrm{C}$ age of the "insoluble" fractions as a function of sample position is shown in Figure 2 , where the position of the elm decline is marked with an arrow. The width of each sample was $2 \mathrm{~cm}$, corresponding to a span of $c a .40 \mathrm{yr}$. These dates should be compared to the 40 -yr movingaverage calibration curve, a section of which is also shown in Figure 2. It is evident that the decline must lie on the right side of the " $5050 \mathrm{BP}$ plateau". The position of the curve relative to the sample sequence corresponds to the elm decline occurring at $3770 \mathrm{BC}$, which gives the best match of the ${ }^{14} \mathrm{C}$ dates to the calibration curve (see below). We note that, at this position, only one of the ${ }^{14} \mathrm{C}$ dates is $>1 \sigma$ from the calibration curve. This technique of wiggle matching in sphagnum peats has also been carried out by Pilcher et al. (1995).

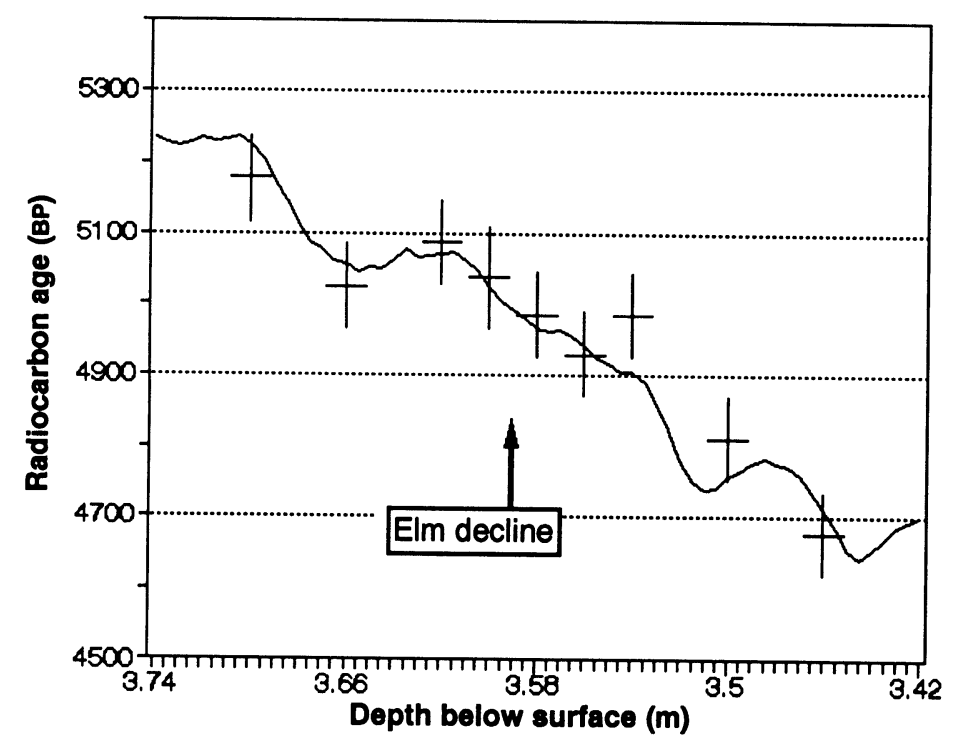

Fig. $2 .{ }^{14} \mathrm{C}$ ages for the nine peat samples from Ageröds Mosse used in this study, indicating sample position relative to the peat surface. The depth scale corresponds to a floating time scale with $1 \mathrm{~cm}=20 \mathrm{yr}$. The sample thickness is $2 \mathrm{~cm}$ in each case, corresponding to an age span of $40 \mathrm{yr}$. Vertical and horizontal bars correspond to the ${ }^{14} \mathrm{C}$ age $\pm 1 \sigma$ and sample thickness, respectively. The 40 -yr moving-average calibration curve, covering a section across the elm decline, is also shown. The position of the curve relative to the sample sequence corresponds to the elm decline occurring at $3770 \mathrm{BC}$. The curve is based on the calibration data set of Stuiver and Becker (1993).

We checked the accuracy of the dates by putting a sample of wood of known age into the measurement series. The ${ }^{14} \mathrm{C}$ age of the test sample was determined to be $2249 \pm 48 \mathrm{BP}$. This sample was part of an international comparison study (Aitchison et al. 1990) and gave an age of $2230 \mathrm{BP}$ as a mean value for $36{ }^{14} \mathrm{C}$ laboratories.

We tested the homogeneity of the sphagnum peat samples by dating the merged alkali-soluble fractions from the $3.54 \mathrm{~m}, 3.56 \mathrm{~m}, 3.58 \mathrm{~m}$ and $3.62 \mathrm{~m}$ levels, and comparing the dates with the mean val- 
ues of the "insoluble" fractions from these levels. The sphagnum peat samples also contained some remains of Eriophorum vaginatum. To check for possible difference in age between these two species, we took a sample from a parallel core and divided it into two fractions, one of which consisted mainly of fibers of Eriophorum vaginatum, and the other of almost pure sphagnum. Table 1 shows the results of the homogeneity tests. We conclude that there are no significant differences in age between different fractions of the samples.

TABLE 1. Core 1: Mean value of ${ }^{14} \mathrm{C}$ ages of the "insoluble" fractions of peat samples from levels $3.54 \mathrm{~m}, 3.56 \mathrm{~m}, 3.58 \mathrm{~m}$ and $3.62 \mathrm{~m}$, and the ${ }^{14} \mathrm{C}$ ages of the merged alkali soluble fractions from the same levels. Core II: ${ }^{14} \mathrm{C}$ ages of two fractions of a sample from a parallel core. The sample has been divided into one fraction containing mainly Eriophorum vaginatum and one fraction containing almost pure sphagnum.

\begin{tabular}{lc}
\hline Sample identification & ${ }^{14} \mathrm{C}$ age $(\mathrm{yr} \mathrm{BP})$ \\
\hline Core I, 3.53-3.59 m and 3.61-3.63 m & \\
Insoluble fraction & $4995 \pm 30$ \\
Soluble fraction & $4985 \pm 70$ \\
Core II, 3.55-3.62 m & \\
Mainly Eriophorum vaginatum fibers & $4909 \pm 72$ \\
Almost pure sphagnum & $4853 \pm 71$ \\
\hline
\end{tabular}

\section{RESULTS}

The dates were matched with the calibration curve by comparing the Ageröds Mosse set of ${ }^{14} \mathrm{C}$ dates with points on the calibration curve, which are spaced in time along the calendar-year axis corresponding to those given by sample positions in the floating chronology for the peat sequence. The comparison was made successively along the relevant part of the calibration curve. The spacing in real time between the samples was estimated by assuming a deposition rate of $0.5 \mathrm{~mm} \mathrm{yr}^{-1}$. The depth scale in Figure 2 can thus be converted to a floating time scale where each centimeter corresponds to $20 \mathrm{yr}$. Because each sample spans ca. $40 \mathrm{yr}$, the comparison was made with the 40 -yr moving-average calibration curve based on the calibration data set of Stuiver and Becker (1993). For each step we calculated the sum of squares of the differences between our nine dates and the corresponding ${ }^{14} \mathrm{C}$ ages given by the calibration curve. The best match is obtained at the position of the peat sequence that gives a minimum sum of squares. According to Figure 3 , the minimum corresponds to the elm decline's occurrence at $3765 \mathrm{BC}$. Corresponding matches using other time-depth scales ( 15 and $30 \mathrm{yr} \mathrm{cm}^{-1}$ ) showed changes of $<10 \mathrm{yr}$ from this value. Because the lowest sum of squares was obtained with the original assumption of a deposition rate corresponding to a depth scale of 20 $\mathrm{yr} \mathrm{cm}^{-1}$, we accepted the $3765 \mathrm{BC}$ date as the calendar age for the elm decline in Ageröds Mosse.

$\chi^{2}$ statistics (Pearson 1986) can be used to estimate confidence limits for the result. Calculations indicate that sums of squares < ca. 20,000 (see Fig. 3) are valid with 68\% (1 $\sigma)$ probability. This would give the interval 3753-3780 BC for the elm decline in Ageröds Mosse. We must also add other small uncertainties, e.g., in the assumption of constant peat growth of $0.5 \mathrm{~mm} \mathrm{yr}^{-1}$ and in the pollen-analytical determination of the elm decline level of $\pm 1 \mathrm{~cm}$, although they are hard to quantify. If we increase the interval to $3745-3790 \mathrm{BC}$, we should be well inside the 1- $\sigma$ level. This result may be compared with that of Andersen and Rasmussen (1993) who used "wiggle-matching" to determine the "classical" elm decline to have occurred at $3820 \mathrm{BC}$ in a lake in northwest Jutland. 


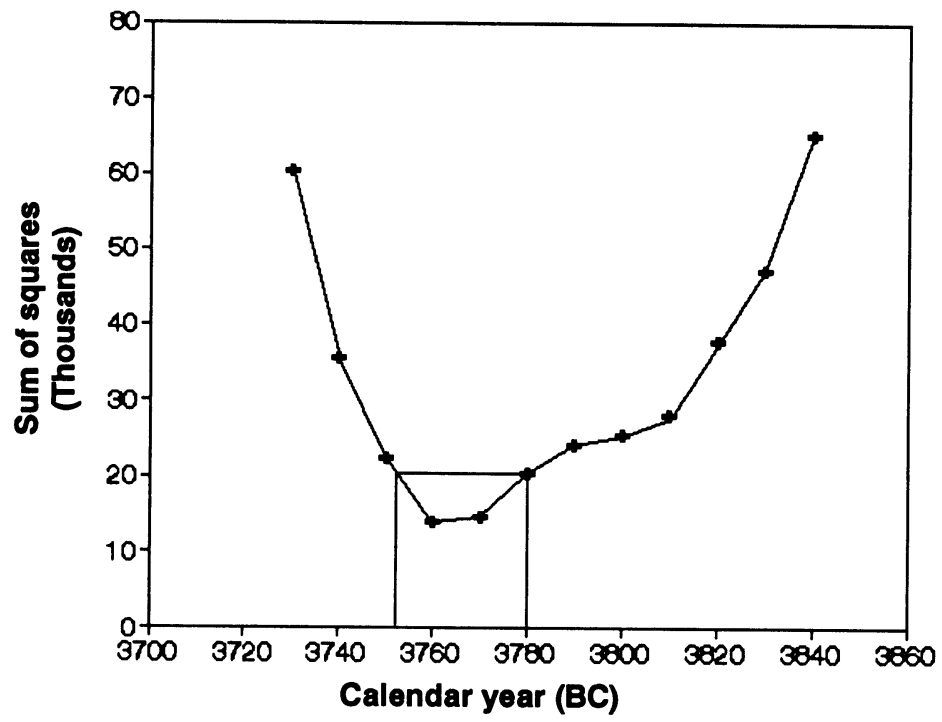

Fig. 3. Sum of squares of $\left(\mathrm{RCA}_{\text {Cal Curve }}-\mathrm{RCA}_{\text {Peat }}\right)$ assuming different calendar year ages for the elm decline in Ageröds Mosse (RCA $={ }^{14} \mathrm{C}$ age). Calibration curve as in Figure 2.

Closely spaced pollen samples show that the elm decline lasted at most 40 calendar years in Ageröds Mosse. This result may be compared to the decrease of $75 \%$ in Ulmus pollen influx over 6-7 $\mathrm{yr}$ found by Peglar in a site of laminated sediments in Britain (Peglar 1993; Peglar and Birks 1993).

\section{ACKNOWLEDGMENTS}

The authors are indebted to Prof. Björn E. Berglund, head of the Department of Quaternary Geology, Lund University, who supported this study. We thank Kerstin Lundahl, who provided the sample preparation and routine operation of the dating equipment. Gunnar Digerfeldt pointed out Tage Nilsson's old coring point in Ageröds Mosse and Per Lagerås and Hans Linderson assisted with the coring. We also thank George Jacobson for correcting the English and for suggestions on improving the manuscript, and finally J. R. Pilcher and Marian Scott for valuable comments on the manuscript.

\section{REFERENCES}

Aitchison, T. C., Scott E. M., Harkness, D. D., Baxter, M. S. and Cook, G. T. 1990 Report on stage 3 of the international collaborative program. Radiocarbon 32 (3): 271-278.

Andersen, S. T. and Rasmussen, K. L. 1993 Radiocarbon wiggle-dating of elm declines in northwest Denmark and their significance. Vegetation History and Archaeobotany 2: 125-135.

Birks, H. J. B. 1986 Late-Quaternary biotic changes in terrestrial and lacustrine environments, with particular reference to north-west Europe. In Berglund B. E., ed., Handbook of Holocene Palaeoecology and Palaeohydrology. Chichester, John Wiley \& Sons: 3-66.

Clymo, R. S., Oldfield, F., Appleby, P. G., Pearson, G. W.,
Ratnesar, P. and Richardson, N. 1990 The record of atmospheric deposition on a rainwater-dependent peatland. Philosophical Transactions of the Royal Society (London) B 327: 331-338.

Nilsson, T. 1964 Standardpollendiagramme und $C^{14-}$ datierungen aus dem Ageröds mosse im mittleren Schonen. Lunds Universitets Årsskrift 59(7):1-52.

Olsson, I. U. 1986 Radiometric dating. In Berglund, B. E., ed., Handbook of Holocene Palaeoecology and Palaeohydrology. Chichester, John Wiley \& Sons: 273-312.

Pearson, G. W. 1986 Precise calendrical dating of known growth-period samples using a "curve-fitting" technique. In Stuiver, M. and Kra, R. S., eds., Proceedings 
of the 12th International ${ }^{14} \mathrm{C}$ Conference. Radiocarbon 28(2A): 292-299.

Peglar, S. 1993 The mid-Holocene Ulmus decline at Diss Mere, Norfolk, UK: a year-by-year pollen stratigraphy from annual laminations. The Holocene 3(1): 1-13.

Peglar, S. and Birks, H. J. B. 1993 The mid-Holocene Ulmus fall at Diss Mere, South-East England: Disease and human impact? Vegetation History and Archaeobotany 2: 61-68.

Pilcher, J. R. 1991 Radiocarbon dating for the Quaternary scientist. Quaternary Proceedings 1: 27-33.

1993 Radiocarbon dating and the palynologist: A realistic approach to precision and accuracy. In Cham- bers, F. M., ed., Climate Change and Human Impact on the Landscape. London, Chapman and Hall: 23-32.

Pilcher, J. R., Hall, V. A. and McCormac, F. G. 1995 Dates of Holocene eruptions from tephra layers in Irish peats. The Holocene 5: 103-110.

Stuiver, M. and Becker, B. 1993 High-precision decadal calibration of the radiocarbon time scale, AD 19506000 BC.In Stuiver, M., Long, A. and Kra, R. S., eds., Calibration 1993. Radiocarbon 35(1): 35-65.

van der Plicht, J. 1993 The Groningen radiocarbon calibration program. In Stuiver, M., Long, A. and Kra, R. S., eds., Calibration 1993. Radiocarbon 35(1): 231237. 